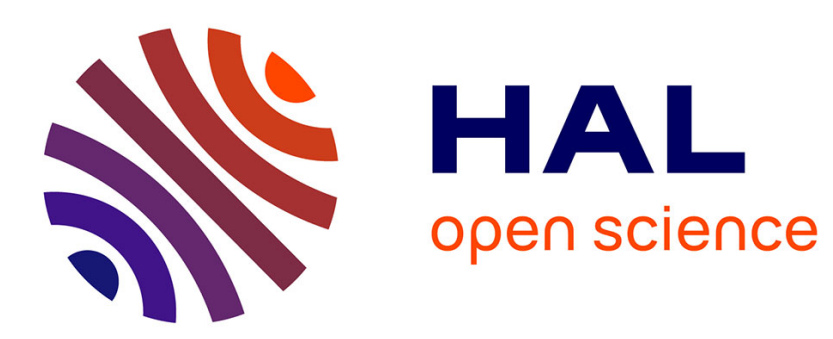

\title{
Digital Revolution or Anthropocenic Feedback?
}

Stéphane Grumbach, Olivier Hamant

\section{To cite this version:}

Stéphane Grumbach, Olivier Hamant. Digital Revolution or Anthropocenic Feedback?. Anthropocene Review, 2017, 5 (1), pp.1-12. 10.1177/2053019617748337 . hal-01227303v2

\section{HAL Id: hal-01227303 \\ https://hal.inria.fr/hal-01227303v2}

Submitted on 2 Jan 2018

HAL is a multi-disciplinary open access archive for the deposit and dissemination of scientific research documents, whether they are published or not. The documents may come from teaching and research institutions in France or abroad, or from public or private research centers.
L'archive ouverte pluridisciplinaire HAL, est destinée au dépôt et à la diffusion de documents scientifiques de niveau recherche, publiés ou non, émanant des établissements d'enseignement et de recherche français ou étrangers, des laboratoires publics ou privés. 


\title{
Digital Revolution or Anthropocenic Feedback?
}

\author{
Stéphane Grumbach (INRIA \& ENS Lyon), Olivier Hamant (INRA \& ENS Lyon) \\ stephane.grumbach@,ens-lyon.fr $\quad$ Olivier.hamant@ens-lyon.fr
}

Manuscript as accepted for publication in The Anthropocene Review

http://journals.sagepub.com/doi/abs/10.1177/2053019617748337

\begin{abstract}
The proliferation of digital technologies increases the density of the communication network among all actors, devices, humans and institutions. It contributes to the emergence of new modes of organization, facilitating direct exchanges between participants and, potentially, frugal use of resources. This profound transformation concurs with the end of abundance with essential natural resources like arable land and various raw materials at stake. Is it just a coincidence? In natural ecosystems, the dearth of resources can increase the complexity through the promotion of sexual (vs. asexual) reproduction, echoing the increased complexity of the digital world. Could resource scarcity also promote the rapid rise of digital platforms, in a feedback loop?
\end{abstract}

\section{Keywords}

Algorithms, intermediation, digital systems, complexity, (a)sexual reproduction 


\section{Introduction}

The Anthropocene is an age of rapid transformations in all areas, from climate to society. Strikingly, this ecological revolution is paralleled by a digital revolution. The rise of the Internet occurred in the 1970s at a time when the ecological movements took momentum. Is this duality only a temporal coincidence?

Whereas the current political trend for "greener" societies offers a possible answer to a world in environmental turmoil, a collection of solutions for "sustainable development" might in fact overshadow a more profound revolution. This is what we question here: what could be the deep, overarching factors explaining the rise of both the ecological and digital revolutions? We find inspiration in biology where responses to resource scarcity have been well documented, with the statistical significance of millions of years of trials, error and selection during evolution. Building on this, we explore whether similar shifts are at play in the digital revolution focusing on the rise of algorithmic intermediation, which reshapes all sectors of our economy and society, and impacts our relation to resources. In short, we propose that the digital and ecological revolutions share many commonalities and may be viewed as one revolution.

\section{Facing resource scarcity in the Anthropocene}

In the Anthropocene, the apparent shortage of natural resources is perceived as a major threat (Steffen et al., 2015; Nørgaard et al., 2010), and is associated with the question of sustainability (Schumacher, 2011). The question of resource scarcity is not new. In 360 B.C., in the Critias, Plato already identified environmental degradation, linking soil erosion to deforestation. Yet, it is mostly in the early 1970s that the question of resources started to be considered more globally, notably though a complex systems approach for earth, proposed by Forrester in "World dynamics" (Forrester, 1971), and subsequently in the "Limits to Growth Report", commissioned by the Club of Rome (Meadows et al., 1972). With the increase of calculus power and data resolution, better predictions from current limits of growth models (Sverdrup et al., 2013) have been made possible. In fact, data gathered since then further support the initial predictions (Turner, 2014).

The question of resource scarcity is also raised by major economic stakeholders. An exhaustive survey on "materials critical to the energy industry" (Zepf et al., 2014) has been commissioned by the industry ${ }^{1}$. At the same time, resource scarcity is one of the topics high on the agenda of international organizations or forums, such as the World Economic Forum ${ }^{2}$, which ranked it as the fourth trend of concerns in 2012 just after the digital communications revolution. Consistently, new indicators have been set up to reflect this evolving paradigm and rethink development beyond GDP (Costanza et al., 2013, Ragnarsdottir et al., 2014). For instance, sustainability, present in Bhutan's Gross National Happiness (GNH), has also been included in the UN Sustainable Development Goals ${ }^{3}$ of 2015. Beyond intellectual and political circles, the shortage of resources has become a subject for a general audience, with recurring themes such as the "sixth extinction of species" or the current increase in carbon dioxide in the atmosphere (Barnosky et al., 2011).

Quantifying earth's resources is a difficult task (Edwards, 2017). Yet, estimations have become increasingly precise. Hubbert's estimations (Hubbert, 1956) for oil production constitute an important landmark in the evaluation of resources and their use. Based on stock 
and production rates, they led to the now famous concept of "peak oil". This work, first valued as a scientific tool, was ignored for a long period by policy makers. However, in 2004, the International Energy Agency estimated that the peak for conventional oil would be reached around 2006, while unconventional and exotic reserves would keep the production high for a longer period (Al-Husseini, 2009; Aleklett, 2012; Campbell and Wöstmann, 2013), paving the way for a large adoption of such approaches. Hubbert's method has been successfully used for other resources such as certain metals (Sverdrup and Ragnarsdóttir, 2014; Gordon et al., 2006; Bardi and Pagani, 2007; Bardi, 2011, 2014). Beyond extracted raw materials, it has been estimated that humans now harvest at least $40 \%$ of the primary production/biomass in industrialized countries, and this number reaches $90 \%$ in intensive crop regions (Haberl et al., 2004).

If the measures of natural resources have made tremendous progress in the last decades, the dependencies between resource consumption and the development of the economy and the society are still subject to different theories. At the end of the 18th century, in his famous Essay on the principle of population as it affects the future improvement of society, Malthus, noting that the world is finite, considered the relation between limits on resources and population growth: "The power of population is indefinitely greater than the power in the Earth to produce subsistence for man" (Malthus, 1809). The rapid evolution of human population, which almost doubled during the 19th century, has tripled since WWII (Steffen et al., 2015) and triggered alternative causalities.

Malthus' followers developed economic models based on the causal relations between agriculture and population levels. Some alternative models departed from neo-Malthusianism, and envisioned a different causality. This is the case in particular of the model proposed by Ester Boserup (Boserup et al., 1983; Boserup, 2005), who investigated the inverse causality and more subtle relationships between population changes and changes in agriculture production. In particular, studying early agricultural practices, she proposed that population increase is in fact the driver of new developments in agriculture. More generally, a limit of Malthus' model is to consider the relation between humanity and resources in a vertical, binary and closed, system, whereas societies are interdependent and can have non-linear relations to resources. In other words, horizontal interactions within societies can generate local impact and somewhat counterintuitive effects. This is illustrated by the Jevons paradox which states that technological improvement does not necessarily lead to resource frugality thanks to efficiency, but instead may lead to an increased consumption of resources, as Jevons noted was the case for coal-use in the mid nineteen century. Today, there is an abundance of such examples. Installing extra insulation in homes reduces energy consumption and heating costs, but might also act as an incentive to spend the surplus for additional home devices. Similarly a hybrid car gets better gas mileage, but the car owner might be inclined to drive more because it becomes cheaper and the gas-consumption guilt is assuaged (Edwards, 2017).

One of the most worrying predictions derived from similar effects is that humanity's intense interaction with the ecosystems may provoke unexpected large-scale consequences. In particular, Barnosky et al. advocate that the increasing land use for biomass production that is harvested by humans and not injected back into the ecosystem could cause dramatic state shifts within the coming decades (Barnosky et al., 2012), pushing the system beyond a tipping point, with dramatic societal consequences.

Analyzing how humanity faces resource scarcity thus raises the issue of feedback mechanisms 
that may promote or hinder resource homeostasis, as well as the societal impact associated with such transformations. To explore this question, we take a detour through the biosphere, as strategies to face resource scarcity and reach homeostasis have been selected through millions of years of evolution. They are now well documented and may help understand our relation to resource homeostasis.

\section{Facing resource scarcity in the biosphere: Increased complexity of the network topology}

Reproduction is a natural topic when dealing with resources because it is the primary regulator of population growth, it relates to heredity and the acquisition of new biological functions during evolution, and it is the most emblematic defining feature of life. Interestingly, reproduction modes are correlated with resource availability.

Sexual reproduction has been positively correlated to resource scarcity, when considering living organisms, which can shift between asexual and sexual reproduction modes (Scheu and Drossel, 2007). Phytophagous insects (Normark, 2003) and aquatic filter feeders, such as water fleas and monogonont rotifers (King, 1980), can indeed switch from asexual to sexual reproduction when food resources become scarce. Conversely, asexual reproduction dominates among the soil decomposers, i.e., in an environment that is abundant in resources. Sexual reproduction has never been reported in some of these soil species (Bell, 1988). Similarly, aquatic cyanobacteria and some algae reproduce asexually and form huge "blooms" in both freshwater and marine environments when resources are abundant: freshwater algal blooms usually result from an excess of nitrate and phosphate. Conversely, and because such blooms are often toxic, their management always involves a constraints on nitrogen and phosphorus (Paerl et al., 2001).

The selection of such a reproductive strategy suggests that a feedback exists, i.e., that sexual reproduction positively addresses the issue of resource scarcity. By involving the search for sexual partners and by constantly exposing and reshuffling the various genetic alleles in a population over several generations, sexual reproduction contributes to a form of horizontal resilience. The "tangled bank hypothesis" (Koella, 1988; Bell, 1982) asserts that sexual reproduction leads to the production of a wider variety of organisms that can use a broader spectrum of resources. Sexual reproduction thus leads to the production of offspring that can feed on additional resources. This represents a major adaptive advantage when resources are scarce (Scheu and Drossel, 2007).

Conversely, and as mentioned above, asexual reproduction is often associated with resource abundance. This strategy is by far the most efficient way to colonize a site rapidly: because males are not produced, all the offspring are productive, and if the environment features remain stable, this strategy also ensures the production of optimally adapted individuals. However asexual reproduction also generates offspring that compete for the same resources. The only way complete competitors can coexist is if resources are permanently abundant (Hardin et al., 1960). It seems therefore that observations, models and evolutionary perspectives converge towards a paradigm in which resource scarcity promotes a form of horizontal resilience in ecosystems, which in turn promotes diversification and adaptation to new resources.

Looking now at the consequences of such an adaptive strategy, one may wonder whether switching between asexual and sexual reproduction could aggravate the threat on resources: 
by increasing the number of niches, resources could become scarce more rapidly. While we cannot completely exclude that possibility, it is more likely that the diversification of niches instead increases the degree of interdependency in the ecosystem network and thus reduces the threat on resources. In an ecosystem with only one species, the growth of the population only depends on the relation between that species and its resources, and thus the resource could be completely depleted. In an ecosystem with multiple species, the amount of resources that is used by one species depends on the byproducts and activity of the other species. In other words, a more complex ecosystem forces frugality on its populations, because of interdependence.

Altogether, these biological data suggest that the promotion of the ecosystem's complexity does not appear randomly, but can instead be, at least in part, the product of a large scale environmental feedback. If increasing connectivity and complexity can be fueled by resource scarcity in the biosphere, is it also relevant in the "technosphere" facing resource scarcity?

\section{Algorithmic intermediation: increasing complexity in the technosphere}

Peter Haff introduced the concept of technosphere (Haff, 2014) in a way analogous to the spheres of earth sciences. The technosphere encompasses all interlinked Human build systems, including transformation of natural resources, energy production, transportation, agriculture, administration, etc. It forms a complex system of interdependent actors, which relies on information exchanges for control and command.

The technosphere has evolved with the increasing connectivity in the communication graph. The use of electricity to encode and convey messages, allowed high speed and long distance communication. The telegraph, developed in the first half of the 19th century, permitted pointto-point exchanges. Not only was the speed of communication increased, but it also became reliable. In the early 20th century, the development of radio made it possible for one station to reach a global population. Television then enriched the content. Large-scale synchronization of information became easy and spread to almost the entire planet.

Beyond communication technologies, the parallel development of computers allowed for automatic processing of information, starting with electromechanical devices used at the end of the 19th century for census. The introduction of electronic devices in the 1940s constituted a breakthrough, which paved the way for complex programmable devices. Computing power has increased exponentially in the last half century, following a prediction made by Gordon Moore in the mid 1960s. The continuous growth reached most technological aspects of computing: transistor density, speed, memory capacity, etc. As a result, while prices were decreasing, new classes of computers emerged, as was anticipated in the 1970s by Gordon Bell, leading to new applications. Technological progress allowed the development of cheap, small, and powerful devices, which could be embedded anywhere. At the turn of the last century, mobile devices carried by humans became ubiquitous, and information technologies were embedded into numerous devices, outnumbering the number of people on earth. It is estimated that in 2020, 50 billion devices will be connected to the "Internet of things", which will progressively become aware of its context (Evans, 2011, Perera et al., 2014).

The miniaturization and sophistication of devices, together with the establishment of the world wide web in the early 1990s, increased the number of lateral connections in a global digital system, steadily resembling a giant ecosystem. Knowledge was made accessible to all, 
thanks to search engines and online encyclopedia. With the advent of the Web 2.0 (O'reilly, 2007), the production of knowledge itself was made possible to all, thus closing the loop: information users also became information providers. The Web 2.0 also gave rise to social networks, and therefore to a horizontal connection between people, devices, as well as immaterial goods, with sophisticated means to find and address individuals or groups of people. In other words, we entered the age of "algorithmic intermediation".

Intermediation is the art of connecting people to the services they need, or that might be useful to them (Rochet and Tirole, 2003; Roth and Sotomayor, 1992; Caillaud and Jullien, 2003). Even if intermediation existed in the pre-digital era, it was at a different scale, orders of magnitude more modest. For instance, banks intermediate between lenders and borrowers. What has changed in the digital era is the capacity to reach both humans and devices, globally, in real time and with personalized services. Algorithmic intermediation now constitutes the beating heart of digital systems connecting people as well as devices to a global network, thus making them interdependent. In this new era, the roles can also be exchanged, a consumer of services becoming a provider of services, as in carpooling systems for instance. Conversely, traditional intermediaries such as newspapers, transportation corporations, etc. are at stake, because their business model is collapsing.

\section{The datasphere: a global, locally interconnected, ecosystem?}

At this stage, one may question the exact status of algorithmic intermediation and its impact on societies. Is it really a fundamental change in paradigm or simply a passing trend?

The datasphere is formed by all data carried by digital systems, independently of who controls them. It contains all information and knowledge accessible by either people or machines. The steady increase in energy consumption by the information and communication industry demonstrates the growing importance of the datasphere. It is now estimated that information technologies exceed $10 \%$ of the world's electricity consumption (Mills, 2013). Measures have been proposed to evaluate the energy intensity in terms of data volume, showing that at the core network, it is around $0.05 \mathrm{kWh} / \mathrm{GB}$ (Schien and Preist, 2014; Schien et al., 2015). A query on the search engine 4 amounts to $0.0003 \mathrm{kWh}$, which corresponds to what the human body burns in ca. 10 seconds given that the average adult needs amounts to about $8000 \mathrm{~kJ}$ a day of energy from food. Some of the new appliances, such as iPhones, consume more energy than traditional ones, and their needs now compare to that of standard household appliances such as refrigerators (Walsh, 2015). The steep slope of energy consumption may in fact question the planet's ability to support ever-increasing algorithmic intermediation.

At the economic level, intermediation actors already occupy a central position. Following their inception in the late $90 \mathrm{~s}$, their role has been rapidly increasing since the beginning of this millennium. At the stock exchange, their capital grows at unprecedented speed ${ }^{5,6}$, reaching the first ranks and progressively evicting the crude oil industry: since second quarter of 2017, seven of the top ten capitalizations were algorithmic intermediation platforms, while a decade earlier, five crude oil corporations were among the top ten. In other words, by challenging energy industry, digital corporations are on the verge to become as fundamental as energy production. In this context, the recent decision of the Rockefeller foundation ${ }^{7}$ to end its support to fossil energy and embrace renewable energy is emblematic of the growing revolution. Beyond energy consumption and market capitalization, it is by the significant 
number of its users, in the billions, that intermediation platforms have the most visible impact. This revolution is neither restricted to people nor to urban environments. The part of land that is not massively inhabited but mostly used for agricultural production is also being increasingly connected. Powerful actors now emerge in the rural world (Grumbach, 2015), which collect data relevant to agriculture, both from external agencies (e.g. weather report) and from local sensors (e.g. hygrometer) in the fields. It uses predictive models to provide services to its customers, through a downstream data flow. Its services address short-term issues such as watering and pests, as well as long-term issues such as choices of crops. Nearly 45 percent of all corn and soybean acres planted in the U.S. are under the control of one platform ${ }^{8}$. In short, algorithmic intermediation clearly reshapes societies and their relation to resources in the long term.

\section{The digital revolution as a product of two positive feedback mechanisms}

Why does the digital revolution happen now? Beyond the efficiency that horizontal and personalized services offer, it seems that other factors contribute to make this transition inexorable. We explore two intrinsic feedback mechanisms that contribute to the increasing complexity in the organization of society.

The first feedback mechanism relates to the quantity and quality of data. One of the most striking consequences of the proliferation of information and communication technologies is the exponential increase in the production of data. Data has become a fundamental resource, one of the main assets today. We are entering the zettabyte era (i.e., 10 to the power of 21 bytes), with volumes of data increasing by orders of magnitude ${ }^{9}$. The digital corporations that have the largest impact are those which combine data with various traces of users activity on the corporation's platform, i.e., data that were not transmitted purposely. Such activity traces have given rise to extremely valuable services, which can either contribute to improving initial services through personalization, or lead to the development of completely new services, which at first glance might appear very distant from the original services. The search engine offers a good example of such a phenomenon. While its main function is to give access to knowledge, by its capacity to direct more relevant ads, it also revolutionized the world of advertisement. From a single message addressed to all, the system shifts to customized lateral connections: better services enable better harvesting of data, and conversely, with more personalization, better services can be offered.

The second feedback mechanism relates to trust. Algorithmic intermediation not only allows the identification of complementary needs in horizontal networks between actors, it also ensures trust in the newly established relation, thus making it reliable and efficient. Trust is a necessary element for exchanges, whether economic or social. Fukuyama (Fukuyama, 1996) showed the importance of trust and the cultural variations and their impact on different human groups. A new notion of trust is emerging with intermediation actors, which is based on the recommendation people make of the services and of other users. A service to share resources such as carpooling for instance has only become possible because intermediation actors are offering guarantees on both drivers and passengers, which are established on the evaluation of previous users. While trust has been ensured in most cultures by vertical organizations, in the digital world trust is ensured at the horizontal level, by peers evaluating others. Interestingly, like activity traces emerging from personalized intermediation and further reinforcing the 
power of algorithmic intermediation, trusting complete strangers is also a side effect of horizontal, personalized intermediation and it is also fueling the development of algorithmic intermediation, in a second feedback loop.

Note that negative feedback is also at play, which may constrain the future development of algorithmic intermediation. As mentioned above, the rapid rise in energy consumption due to information technology may soon act as a limiting factor of digital platforms ${ }^{10}$. Other negative feedback includes conflicts between distributed algorithmic platforms and centralized government as well as new forms of criminality and cyber-threats.

\section{The rise of algorithmic intermediation as a consequence of resource scarcity?}

The datasphere not only feeds on resources, it may also enforce a more frugal use of resources. Resources are now surveyed at an unprecedented spatial and temporal resolution, allowing increased efficiency in their management. For instance, building automation could allow the monitoring and reduction of energy consumption in households. Smart cities, equipped with sensors in the infrastructure, may lead to more rational governance of resources, guided by algorithms. Smart grids also constitute a good illustration of such phenomenon, with a shift from a centralized energy producer and numerous consumers, to a horizontal network of producers and consumers.

A key question arises at this stage: Because the datasphere can promote homeostasis through a horizontal control of resources, could it also contribute to adjust human decisions in a world where resources are scarce? Large parts of financial markets are now under the control of algorithms (Hendershott et al., 2011; Chaboud et al., 2014), and small market crashes have even been attributed to transient algorithmic failures. One might wonder whether in the future humans will gradually outsource most decision-making to algorithmic intermediation platforms.

It is likely that the technosphere, and its algorithmic component, will become increasingly autonomous. There are several reasons for that. First algorithms access an unmatched amount of data, on which they can perform increasingly powerful data analytics. The rapid development of Artificial Intelligence may likely shift the control of devices and systems from humans to machines in an increasing number of sectors. The relevance of their matching and the efficiency of their predictions make them indispensable in most sectors. But there is more: they also impose new norms. The new norms imposed by the datasphere could serve global objectives, and promote new values, disrupting local rules. Their wide adoption by the population may give them a new kind of legitimacy - the legitimacy of the technosphere that goes beyond national borders and sovereign powers (Faravelon and Grumbach, 2016).

In biology, horizontal resilience strategies such as sexual reproduction when resources become scarce are promoted to the detriment of individual benefits. Typically, sexual reproduction also entails a risk of having offsprings with disabilities, and thus a lower fit to the current environment at the individual level, while ensuring genetic diversity and thus resilience at the population scale. Biology during evolution has selected strategies that allow survival in the long term, not comfort in the short term. A homeostatic technosphere in the Anthropocene thus raises the question of a new form of governance. 


\section{Conclusion}

Our claim in this paper is that the rapid rise of algorithmic intermediation may be in part fueled by a feedback from resource scarcity. Looking ahead, the digital revolution could have profound implications in the Anthropocene. It is changing the socio-economic organization and it may also reduce our forcing on resources in the near future. Perhaps more fundamentally, algorithmic intermediation is shifting where the power resides, thus questioning the very nature of the Anthropocene. It is thus worth considering the possibility that the datasphere may increasingly decide for our future and potentially conflict with shortterm or local desires. We might thus enter an era where algorithms concentrate the true power of the technosphere, accurately assessing resource availability and feeding back on society more and more independently from human decisions. While addressing resource scarcity and providing new forms of governance, algorithms might reduce the Anthropocene to a transient anomaly.

\section{Acknowledgments}

We thank Sowmya Kadandale for proofreading this manuscript.

\section{Notes}

1. http://www.bp.com/content/dam/bp/pdf/sustainability/group-reports/ ESC_Materials_handbook_BP_Apr2014.pdf

2. http://reports.weforum.org/global-agenda-survey-2012/trends/scarcity-of-resources/

3. https://sustainabledevelopment.un.org/

4. https://googleblog.blogspot.fr/2009/01/powering-google-search.html

5. The valuation of Uber is approaching half of the one of IBM

6. Seven intermediation platforms among the top 10 market capitalisations at the end of the third quarter 2017. Figures are in USD millions : Apple 791,726; Alphabet 664,550 ;

Microsoft 568,965 ; Amazon 459,435 ; Alibaba Group 436,850 ; Tencent 405,007 ; Facebook 399,946 .

\section{7. founder of Standard Oil (then Esso, then ExxonMobil)}

8. The climate corporation: In a 2015 press release, https://www.climate.com/company/pressreleases/digital-agronomic-services-platform/, it was announced that more than 75 million row crop acres had

been mapped in the digital agriculture platform, up from 50 million acres in 2014.

9. http://www.cisco.com/c/en/us/solutions/collateral/service-provider/visual-networkingindex-vni/VNI_Hyperconnectivity_WP.html

10. Electronic devices consume as much energy as household appliances. Katherine Tweed, 2013, A Smart Phone Uses as Much Energy as a Refrigerator?

https://spectrum.ieee.org/energywise/energy/environment/smart-phones-uses-as-muchenergy-as-a-refrigerator 


\section{References}

Al-Husseini M (2009)World production of conventional petroleum liquids to 2030: A comparative overview. GeoArabia 14: 215-267.

Aleklett K (2012) Peeking at peak oil. Springer Science \& Business Media.

Bardi U (2011) The limits to growth revisited. Springer Science \& Business Media.

Bardi U (2014) Extracted: How the quest for mineral wealth is plundering the planet. Chelsea Green Publishing.

Bardi U and Pagani M (2007) Peak minerals. The Oil Drum 15.

Barnosky AD, Hadly EA, Bascompte J, Berlow EL, Brown JH, Fortelius M, Getz WM, Harte J, Hastings A, Marquet PA et al. (2012) Approaching a state shift in earth/'s biosphere. Nature 486(7401): 52-58.

Barnosky AD, Matzke N, Tomiya S, Wogan GO, Swartz B, Quental TB, Marshall C, McGuire JL, Lindsey EL, Maguire KC et al. (2011) Has the earth/'s sixth mass extinction already arrived? Nature 471(7336): 51-57.

Bell G (1982) The masterpiece of nature: the evolution and genetics of sexuality. London, UK: Croom Helm. .

Bell G (1988) Sex and death in protozoa — the history of an obsession. Cambridge, UK: Cambridge University Press.

Boserup E (2005) The conditions of agricultural growth: The economics of agrarian change under population pressure. Transaction Publishers.

Boserup E, Makhoul N, Munn R, Srinivasan T, Robinson J and Rocha C (1983) Population and technological change: A study of long-term trends. International Journal of Health Services 13(1): 15-31.

Caillaud B and Jullien B (2003) Chicken \& egg: Competition among intermediation service providers. RAND journal of Economics : 309-328.

Campbell CJ and Wöstmann A (2013) Campbell's Atlas of Oil and Gas Depletion. Springer.

Chaboud AP, Chiquoine B, Hjalmarsson E and Vega C (2014) Rise of the machines: Algorithmic trading in the foreign exchange market. The Journal of Finance 69(5): 20452084.

Costanza R, McGlade J, de Bonvoisin S, Farley J, Giovannini E, Kibizewski I, Lappe FM, Lovins H, Pickett K, Norris G et al. (2013) The future we really want. Solutions 4: 37-43.

Diamond J (2005) Collapse: How societies choose to fail or succeed. Penguin.

Edwards P.N. (2017) Knowledge Infrastructures for the Anthropocene. The Anthropocene review. $4: 34-43$

Evans D (20) The internet of things. How the Next Evolution of the Internet is Changing Everything, Whitepaper, Cisco Internet Business Solutions Group (IBSG).

Faravelon A and Grumbach S (2016) Platforms as governments. In: Internet, Politics, and Policy conference. Oxford Internet Institute.

Forrester JW (1971) World dynamics, volume 59. Wright-Allen Press Cambridge, MA. 
Fukuyama F (1996) Trust: The social virtues and the creation of prosperity, volume 457. Free press New York.

Gordon RB, Bertram M and Graedel T (2006) Metal stocks and sustainability. Proceedings of the National Academy of Sciences of the United States of America 103(5): 1209-1214.

Grumbach S (2015) Big data and agriculture, from bytes to crops and conversely. ODBMS.

Haberl H, Schulz NB, Plutzar C, Erb KH, Krausmann F, Loibl W, Moser D, Sauberer N, Weisz H, Zechmeister HG et al. (2004) Human appropriation of net primary production and species diversity in agricultural landscapes. Agriculture, Ecosystems \& Environment 102(2): 213-218.

Haff P (2014) Technology as a geological phenomenon: implications for human well-being. Geological Society, London, Special Publications 395(1): 301-309.

Hardin G et al. (1960) The competitive exclusion principle. Science 131(3409): 1292-1297.

Hendershott T, Jones CM and Menkveld AJ (2011) Does algorithmic trading improve liquidity? The Journal of Finance 66(1): 1-33.

Hubbert MK (1956) Nuclear energy and the fossil fuel. In: Drilling and production practice. American Petroleum Institute.

King CE (1980) The genetic structure of zooplankton populations. Evolution and ecology of zooplankton communities. University Press of New England, Hanover : 315-329.

Koella JC (1988) The tangled bank: the maintenance of sexual reproduction through competitive interactions. Journal of Evolutionary Biology 1(2): 95-116.

Malthus TR (1809) An essay on the principle of population, as it affects the future improvement of society, volume 2 .

Meadows DH, Meadows DL, Randers J and Behrens WW (1972) The limits to growth. New York 102.

Mills MP (2013) The cloud begins with coal, big data, big networks, big infrastructure, and big power. Digital Power Group. Online at: http://www.tech-pundit.com/wp-content/uploads/ 2013/07/Cloud_Begins_With_Coal.pdf.

Nørgaard J, Ragnarsdóttir KV and Peet J (2010) The history of the limits to growth. Solutions Journal 1(2): 59-63.

Normark BB (2003) The evolution of alternative genetic systems in insects. Annual Review of Entomology 48(1): 397-423.

O'reilly $\mathrm{T}$ (2007) What is web 2.0: Design patterns and business models for the next generation of software. Communications \& strategies (1): 17.

Paerl HW, Fulton RS, Moisander PH and Dyble J (2001) Harmful freshwater algal blooms, with an emphasis on cyanobacteria. The Scientific World Journal 1: 76-113.

Perera C, Zaslavsky A, Christen P and Georgakopoulos D (2014) Context aware computing for the internet of things: A survey. Communications Surveys \& Tutorials, IEEE 16(1): 414454.

Ragnarsdottir K, Costanza R, Giovannini E, Kubiszewski I, Lovins H, McGlade J, Pickitt K, Roberts D, de Vogli R and Wilkinson R (2014) Beyond gdp. exploring the hidden links 
between geology, economics and well-being. Geoscientist 24: 12-17.

Rochet JC and Tirole J (2003) Platform competition in two-sided markets. Journal of the European Economic Association : 990- 1029.

Roth AE and Sotomayor MAO (1992) Two-sided matching: A study in game-theoretic modeling and analysis. 18. Cambridge University Press.

Scheu S and Drossel B (2007) Sexual reproduction prevails in a world of structured resources in short supply. Proceedings of the Royal Society of London B: Biological Sciences 274(1614): 1225-1231.

Schien D, Coroama VC, Hilty LM and Preist C (2015) The energy intensity of the internet: edge and core networks. In: ICT Innovations for Sustainability. Springer, pp. 157-170.

Schien D and Preist C (2014) A review of top-down models of internet network energy intensity. In: ICT for Sustainability 2014 (ICT4S-14). Atlantis Press.

Schumacher EF (2011) Small is beautiful: a study of economics as if people mattered. Random House.

Steffen W, Broadgate W, Deutsch L, Gaffney O and Ludwig C (2015) The trajectory of the anthropocene: the great acceleration. The Anthropocene Review 2(1): 81-98.

Sverdrup HU, Koca D and Ragnarsdóttir KV (2013) Peak metals, minerals, energy, wealth, food and population: Urgent policy considerations for a sustainable society. Journal of

Environmental Science and Engineering. B 2(4B): 189.

Sverdrup HU and Ragnarsdóttir KV (2014) Section 5. phosphorus: The story of how rocks, soil and oil create people. Geochemical Perspectives 3(2): 278-293.

Turner G (2014) Is global collapse imminent? an updated comparison of the limits to growth with historical data. Melbourne Sustainable Society Institute, Research Paper (4).

Walsh B (2015) The surprisingly large energy footprint of the digital economy.

Zepf V, Reller A, Rennie C, Ashfield M and Simmons J (2014) Materials critical to the energy industry. An introduction, $2^{\text {nd }}$ edn. London, United Kingdom. 